\title{
Bridging Digital Divides: a Literature Review and Research Agenda for Information Systems Research
}

\author{
Polyxeni Vassilakopoulou ${ }^{1}$ (D) Eli Hustad ${ }^{1}$ (D) \\ Accepted: 6 December 2020 \\ (C) The Author(s), under exclusive licence to Springer Science+Business Media, LLC part of Springer Nature 2021
}

\begin{abstract}
Extant literature has increased our understanding of the multifaceted nature of the digital divide, showing that it entails more than access to information and communication resources. Research indicates that digital inequality mirrors to a significant extent offline inequality related to socioeconomic resources. Bridging digital divides is critical for sustainable digitalized societies. In this paper, we present a literature review of Information Systems research on the digital divide within settings with advanced technological infrastructures and economies over the last decade (2010-2020). The review results are organized in a concept matrix mapping contributing factors and measures for crossing the divides. Building on the results, we elaborate a research agenda that proposes [1] extending established models of digital inequalities with new variables and use of theory, [2] critically examining the effects of digital divide interventions, and [3] better linking digital divide research with research on sustainability.
\end{abstract}

Keywords Digital divide $\cdot$ Digitalization $\cdot$ Digital inequalities $\cdot$ Information systems research $\cdot$ Sustainability

\section{Introduction}

Digital inequalities have emerged as a growing concern in modern societies. These inequalities relate to disparities in access, actual use and use efficacy of digital resources. Digital resources including transformative technologies, such as business analytics, big data and artificial intelligence are key for the transition of societies towards sustainability (Pappas et al. 2018; United Nations 2018). Reducing digital inequalities is critical for sustainable digitalized societies. At a high level, all types of digital inequalities are encompassed in the term digital divide. One of the first uses of the term is traced back in a US government report published in 1999 referring to the divide between those with access to new technologies and those without (NTIA 1999). The term was soon broadened to signify the "gap between those who can effectively use new information and communication tools, such as the Internet, and those who cannot" (Gunkel 2003). Overall, the term digital divide

Polyxeni Vassilakopoulou

polyxenv@uia.no

Eli Hustad

eli.hustad@uia.no

1 University of Agder, Kristiansand, Norway includes digital inequalities between individuals, households, businesses or geographic areas (Pick and Sarkar 2016; OECD 2001). The conceptual broadness of the term aims to capture a multifaceted economic and civil rights issue in an era of continuous efforts to digitalize society. The ongoing digitalization poses a challenge for individuals who are not fully capable of using digital resources and may feel partially excluded or completely left out of the society.

Extant research has contributed insights on the different aspects of the digital divide phenomenon. In the past, the digital divide literature was mostly driven by policy-oriented reports that focused on access. Nevertheless, scientific research expanded to digital inequalities beyond access. Researchers foregrounded digital inequalities related to knowledge, economic and social resources, attributes of technology such as performance and reliability, and utility realization (DiMaggio et al. 2004; Van Dijk 2006; Van Deursen and Helsper 2015). In technologically and economically advanced settings, digital divides seem to be closing in terms of access, but inequalities that affect people's ability to make good use of digital resources persist (Lameijer et al. 2017; Hsieh et al. 2011; Bucea et al. 2020). As digitalization becomes increasingly pervasive in work and everyday life, concerns are rising about continuing inequalities within societies that are at the digital forefront. At the same time, in lowresource settings there are still significant access issues. For instance, in the least developed countries (as defined by the 
United Nations) only 19 per cent of individuals had online access in 2019 while in developed countries, close to 87 per cent of individuals access the internet (Int.Telecom.Union 2019). Beyond big differences across settings in terms of access, low-resource settings are tormented by particular political, economic and social conditions inflicting digital divides (Venkatesh et al. 2014; Srivastava and Shainesh 2015; Luo and Chea 2018). Overall, prior research has shown that the modalities of digital inequalities are context-specific and it is important to be explicit about the context when researching the digital divide (Barzilai-Nahon 2006). This work is focused on digital divide research within settings with advanced technological infrastructures and economies.

The digital divide is an exemplary sociotechnical phenomenon and has attracted the interest of Information System (IS) researchers. IS research examines more than technologies or social phenomena, or even the two side by side; it investigates emergent sociotechnical phenomena (Lee 2001). Hence, IS researchers are well-positioned to study the digital divide phenomenon and have been producing a significant volume of related research. Nevertheless, no systematic review of the IS body of literature on the digital divide exists. Our study identifies, analyses, and integrates a critical mass of recent IS research on the digital divide focused on settings where the technological infrastructures and economies are advanced. To ensure a robust result, we performed a systematic literature review (Kitchenham 2004) guided by the following question: What are the key findings identified in extant IS research related to the digital divide in contemporary technologically and economically advanced settings?

Our contribution is threefold. First, we identify recurring digital divide factors for population groups threatened by digital inequalities. The factors identified indicate that digital inequalities frequently mirror offline inequalities (for instance, in terms of socioeconomic resources, knowledge and physical abilities). Second, we present measures proposed in the literature and organize them in three key intervention domains that can contribute to closing the gap (related to policies, training initiatives and tailored design). Finally, as a third contribution, we identify areas for future research providing a research agenda.

The remainder of the paper is organized as follows. First, we present the method used for selecting and analyzing the articles for this review. Then, we offer a synthesis of our findings related to digital divide factors and related measures and present them in a concise concept matrix. We continue by discussing the implications for further research and we end with overall concluding remarks.

\section{Method}

The literature review is conceptual providing a synthesis of prior research and identifying areas for future research (Ortiz de Guinea and Paré 2017; Schryen et al. 2015). It includes research published during the last decade (2010-2020). The approach followed is based on the three-step structured literature review process proposed by Kitchenham (2004). Specifically, the three-step process includes: (a) planning the review, where a detailed protocol containing specific search terms and inclusion/exclusion criteria is developed, (b) conducting the review, where the identification, selection, quality appraisal, examination and synthesis of prior published research is performed and (c) reporting the review, where the write-up is prepared. We used these steps as our methodological framework. In addition, we utilized principles suggested by Webster and Watson (2002) for sorting the articles included in the review. Following these principles, we identified key concepts and created a concept-centric matrix that provides an overview of the literature reviewed.

To identify articles to be reviewed, we searched for "Digital" and "Divide" in the abstract, title or keywords within published Information Systems research. Inclusion and exclusion criteria were established to reduce selection bias, guarantee the quality of the papers selected and increase the review validity. Peer-reviewed, empirical papers, written in English were included. Conceptual papers that lack empirical evidence and papers focusing on the digital divide in developing countries were excluded. Figure 1 provides an overview of the selection process. To ensure a good coverage of Information Systems research we searched within the eight top journals in the field i.e. the basket of eight (AIS 2019). The journals included in the basket are: European Journal of Information Systems, Information Systems Journal, Information Systems Research, Journal of AIS, Journal of Information Technology, Journal of MIS, Journal of Strategic Information Systems and MIS Quarterly. Additionally, we searched within the journal Communications of the Association for Information Systems (CAIS) which has a key role within the IS research community communicating swiftly novel, original research. We also included in our search the journal Information Technology (IT) \& People because it focuses on IS research that explores the interplay between technology individuals and society and the journal Information Systems Frontiers because it covers behavioural perspectives on IS research. Both journals are high quality IS outlets especially relevant for research on the digital divide. Furthermore, we included in our search the conferences of the Association of Information Systems (ICIS, ECIS; AMCIS; PACIS) and the Hawaiian International Conference on System Sciences (HICSS). We utilized Scopus as our search engine.

In Scopus, we searched for papers from the selected journals and conferences excluding books, book chapters, commentaries, letters and short surveys. For the journal article search, the ISSNs of the selected journals were used for filtering the search results in Scopus. In total, 45 journal papers were identified. For the conference article search, the 
Fig. 1 The literature selection process

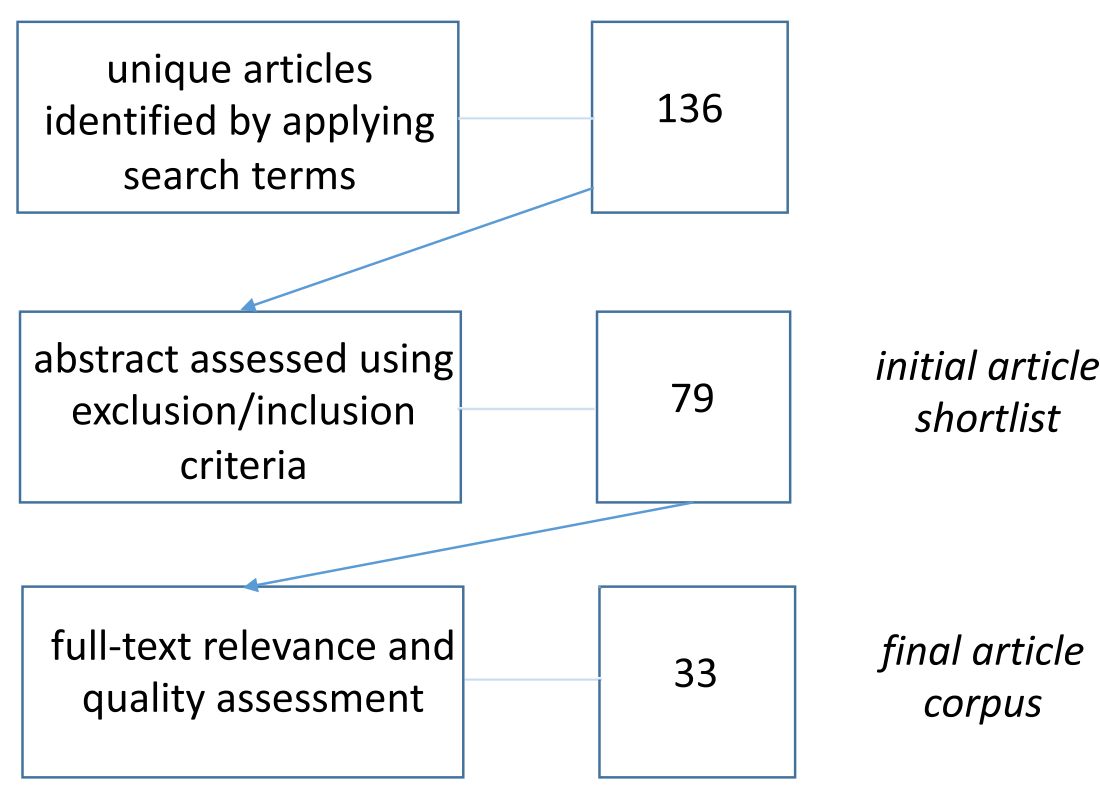

conference names were used in Scopus and 91 conference papers were identified. Overall, the search yielded 136 unique articles in total. The next step was to read the titles and abstracts of the articles identified checking their relevance to the research question. For this step, the exclusion criteria were used. Specifically, we excluded papers that only casually mentioned the digital divide but had a different focus, literature reviews and conceptual papers and papers focused on developing countries. After this step, 79 articles were shortlisted. The full text of each of the shortlisted articles was assessed for relevance applying the inclusion-exclusion criteria to the full content. Additionally, the quality of the research reported was assessed. For the quality assessment, each article's method description was first checked. At this stage, conference papers reporting early stages of ongoing research were removed. In several cases of conference papers that were removed, we found that more mature and extensive results from the same studies were reported in journal articles that were already included in our shortlist and were published after the conference papers. After this step, a final corpus of 33 articles was defined (Table 1). A detailed overview of the reviewed articles is included in an electronic supplementary file that can be accessed in the journal's web site (see Online Resource 1).

After selecting the papers, we analyzed their content. We started with extracting meta-data of the papers such as type of study, year of study, study context, research method and theoretical framework applied. In addition, we identified the study subjects for each paper distinguishing between papers that engage with the general population, or specific groups of people including the elderly and marginalized population groups (e.g. refugees, migrants). We continued with an intra-analysis of the content of the papers by looking for core themes in each paper. The themes that were identified for each paper were registered, and as a next step, we performed an inter-analysis and comparison across papers. Based on the comparison, recurring themes and patterns across the papers were discovered and further categorized. The outcomes of the papers'analysis are presented in the "Results" section that follows.

\section{Results}

This section presents the key findings from the literature reviewed. First, we present the theoretical premises and the methodological approaches of extant publications on the Digital Divide within IS research and their evolution from 2010 to 2020. Table 2 provides an overview of the theories and concepts, methods and data sources in the literature reviewed. Then, recurring digital divide factors are presented for population segments that are particularly digitally challenged (the elderly and marginalized population groups) and also, for the general population. Finally, measures for addressing the digital divide are presented and organized in three key intervention domains (policy measures, education/training and design tailoring). The section also includes a concept matrix which provides an overview of digital divide factors and related measures identified in the literature reviewed (Table 3).

\subsection{Trends, Methods and Theoretical Frames in IS Research on the Digital Divide}

The work of Information Systems' researchers on the digital divide has been influenced by policy-oriented reports that tend to be based on macro-level analyses. This influence is clear in the first half of the 2010-2020 period while in the second half, research extends towards a more complex and contextualized 
Table 1 List of selected articles

\# Reference

1 Abdelfattah, B. M., Bagchi, K., Udo, G., \& Kirs, P. (2010). Understanding the Internet Digital Divide: An Exploratory Multi-Nation Individual-Level Analysis. 16th American Conference on Information Systems AMCIS 2010 Proceedings.

2 Alam, K., \& Imran, S. (2015). The digital divide and social inclusion among refugee migrants: A case in regional Australia. Information Technology \& People, 28(2), 344-365.

3 Aricat, R. G. (2015). Is (the study of) mobile phones old wine in a new bottle? A polemic on communication-based acculturation research. Information Technology \& People, 28(4), 806-824.

4 Bucea, A.E., Cruz-Jesus, F., Oliveira, T., \& Coelho, P. S. (2020). Assessing the Role of Age, Education, Gender and Income on the Digital Divide: Evidence for the European Union. Information Systems Frontiers, 1-15.

5 Burtch, G., \& Chan, J. (2019). Investigating the Relationship Between Medical Crowdfunding and Personal Bankruptcy in the United States: Evidence of a Digital Divide. MIS Quarterly, 43(1), 237-262.

6 Chang, S.-I., Yen, D. C., Chang, I.-C., \& Chou, J.-C. (2012). Study of the digital divide evaluation model for government agencies-a Taiwanese local government's perspective. Information Systems Frontiers, 14(3), 693-709.

7 Choudrie, J., Pheeraphuttranghkoon, S., and Davari, S. (2018), The Digital Divide and Older Adult Population Adoption, Use and Diffusion of Mobile Phones: a Quantitative Study, Information Systems Frontiers, 1-23.

8 Davis, J. G., Kuan, K. K., \& Poon, S. (2020). Digital Exclusion and Divide in the United States: Exploratory Empirical Analysis of Contributing Factors. AMCIS 2020 Proceedings.

9 Dewan, S., Ganley, D., \& Kraemer, K. L. (2010). Complementarities in the diffusion of personal computers and the Internet: Implications for the global digital divide. Information Systems Research, 21(4), 925-940.

10 Díaz Andrade, A., \& Doolin, B. (2016). Information and communication technology and the social inclusion of refugees. MIS Quarterly, 40(2), 405-416.

11 Díaz Andrade, A., \& Techatassanasoontorn, A. A. (2020). Digital enforcement: Rethinking the pursuit of a digitally enabled society. Information Systems Journal.

12 Ebermann, C., Piccinini, E., Brauer, B., Busse, S., \& Kolbe, L. (2016). The Impact of Gamification-Induced Emotions on In-car IS Adoption - The Difference between Digital Natives and Digital Immigrants. 49th Hawaii International Conference on System Sciences (HICSS 2016), IEEE.

13 Fox, G., \& Connolly, R. (2018). Mobile health technology adoption across generations: Narrowing the digital divide. Information Systems Journal, 28(6), 995-1019.

14 Holgersson, J., \& Söderström, E. (2019). Bridging the gap-exploring elderly citizens' perceptions of digital exclusion. ECIS 2019 Proceedings.

15 Hsieh, J.J,, Rai, A., \& Keil, M. (2011). Addressing digital inequality for the socioeconomically disadvantaged through government initiatives: Forms of capital that affect ICT utilization. Information Systems Research, 22(2), 233-253.

16 Klier, J., Klier, M., Schäfer-Siebert, K., \& Sigler, I. (2020). \# JOBLESS\# OLDER\# DIGITAL-Digital media user types of the older unemployed. ECIS 2020 Proceedings.
Table 1 (continued)

\# Reference

17 Lameijer, C. S., Mueller, B., \& Hage, E. (2017). Towards Rethinking the Digital Divide-Recognizing Shades of Grey in Older Adults' Digital Inclusion. ICIS 2017 Proceedings.

18 Ma, J., \& Huang, Q. (2015). Does better Internet access lead to more adoption? A new empirical study using household relocation. Information Systems Frontiers, 17(5), 1097-1110.

19 Middleton, K. L., \& Chambers, V. (2010). Approaching digital equity: is wifi the new leveler? Information Technology \& People, 23(1), 4-22.

20 Niehaves, B., \& Plattfaut, R. (2010). The Age-Divide in Private Internet Usage: A Quantitative Study of Technology Acceptance. 16th American Conference on Information Systems AMCIS 2010 Proceedings.

21 Niehaves, B., \& Plattfaut, R. (2014). Internet adoption by the elderly: employing IS technology acceptance theories for understanding the age-related digital divide. European Journal of Information Systems, 23(6), 708-726.

Park, S., Freeman, J., Middleton, C., Allen, M., Eckermann, R., \& Everson, R. (2015) The multi-layers of digital exclusion in rural Australia. In 48th Hawaii International Conference on System Sciences, HICSS 2015, IEEE

23 Pick, J., \& Azari, R. (2011). A global model of technological utilization based on governmental, business-investment, social, and economic factors. Journal of Management Information Systems, 28(1), 49-84.

24 Pick, J., Sarkar, A., \& Parrish, E. (2018). Internet Use and Online Activities in US States: Geographic Disparities and Socio-economic Influences. In 51st Hawaii International Conference on System Sciences, HICSS 2018, IEEE

Pethig, F., \& Kroenung, J. (2019). Specialized information systems for the digitally disadvantaged. Journal of the Association for Information Systems, 20(10), 1412-1446.

26 Racherla, P., \& Mandviwalla, M. (2013). Moving from access to use of the information infrastructure: A multilevel sociotechnical framework. Information Systems Research, 24(3), 709-730.

27 Reinartz, A., Buhtz, K., Graf-Vlachy, L., \& König, A. (2018). Mechanisms of engagement with, and disengagement from, Internet applications: A qualitative study of online job search. ICIS 2018 Proceedings.

28 Rockmann, R., Gewald, H., \& Haug, M. (2018). Equal Access for Everyone? A Digital Divide Cascade for retired Senior Citizens. ECIS 2018 Proceedings.

29 Sipior, J. C., Ward, B. T., \& Connolly, R. (2011). The digital divide and t-government in the United States: using the technology acceptance model to understand usage. European Journal of Information Systems, 20(3), 308-328.

30 Talukdar, D., \& Gauri, D. K. (2011). Home Internet access and usage in the USA: Trends in the socio-economic digital divide. Communications of the Association for Information Systems, 28(1), 85-98.

31 Wei, K.K., Teo, H.H., Chan, H. C., \& Tan, B. C. (2011) Conceptualizing and testing a social cognitive model of the digital divide. Information Systems Research, 22(1), 170-187.

32 Xiong, J., \& Zuo, M. (2019). How does family support work when older adults obtain information from mobile Internet? Information Technology \& People, 32 (6), 1496-1516. 
Table 1 (continued)

\# Reference

33 Zhao, F., Collier, A., \& Deng, H. (2014). A multidimensional and integrative approach to study global digital divide and e-government development. Information Technology \& People, $27(1), 38-62$.

picture of digital divides. Newer papers tend to ask a wider range of questions related to access and use of information technologies and investigate a greater variety of factors. For instance, skill related factors are explored in about half of both earlier and later studies, but, newer studies tend to additionally explore motivation and personality aspects (about half of the newer studies include such aspects). Interestingly, several of the newer papers only focus on technology use. In these papers, researchers explore the second order digital divide and the extent of inclusion or involuntary exclusion of those that already have access to technologies. Furthermore, most earlier papers tend to investigate the general population while the majority of newer studies focus on specific population groups.

Overall, most of the studies employ quantitative research methods utilizing well-established survey instruments adapted for studying digital inequalities for certain groups (e.g. older adults) or re-using existing data sets from organizations like the International Telecommunication Union, the World Bank and the United Nations. A few studies use a mixed-method approach combining interviews with survey data, while the rest employ qualitative approaches. Well-known technology acceptance models such as TAM (Technology Acceptance Model), UTAUT (Unified Theory of Acceptance and Use of Technology) and MATH (Model of Adoption of Technology in Households) and theories on motivation and human behavior have been used to explore the digital divide. Typical variables included in the investigations are self-efficacy, performance and effort expectancy. Furthermore, social cognitive theories, social support theories and social capital conceptualizations have been used while some of the papers utilize selectively digital divide conceptualizations combined with constructs from social, sociotechnical or economic research.

\subsection{Factors Contributing to the Digital Divide}

The digital divide is often characterized as a digital divide cascade which is nuanced into different types of inequalities including unequal capabilities, engagement, and use outcomes in addition to inequalities of access and use. This points to the importance of identifying and aiming to remedy inequalities in what people are actually able to do and achieve with digital technologies (Burtch and Chan 2019; Díaz Andrade and Doolin 2016). In settings with advanced infrastructures and economy, physical access is not a key source of digital inequalities and IS studies that examine issues of unequal access show that access gaps are closing with the exception of marginalized population groups. Nevertheless, there is still a stark difference between access (first-order divide) and actual use (second-order divide) (Bucea et al. 2020). The latter relates to differences in digital skills, autonomy, social support and the aims of digital technology use (Rockmann et al. 2018). Going beyond socioeconomic demographics, additional personal contributing factors have been identified in the literature related to: (a) motivation, (b) personality traits (e.g. openness, extraversion, conscientiousness), (c) digital skills. Many of the studies reviewed focus on the elderly who are also referred to as "digital immigrants" (as opposed to digital natives that have been interacting with digital technology since childhood). Additionally, several studies focus on marginalized population groups. In the paragraphs that follow, we present research findings organizing them according to the different groups studied.

Elderly Population Although digital technologies have been around for several decades, some of the elderly members of society have difficulties familiarizing with and adopting digital tools and services. Nevertheless, although a decade ago age-related underutilization of IT was significant (Niehaves and Plattfaut 2010), over the years, information and communication technologies (ICTs) have been gradually better integrated in the lives of elderly adults. A recent study on the digital divide related to mobile phone use among old adults in UK found that more than $70 \%$ have adopted smartphones (Choudrie et al. 2018). Specifically, research findings indicate that older adults frequently use internet-related smartphone features such as emailing and browsing although only very few use smartphones to access public services such as the National Health Service. One potential reason for the limited use of specialized web-based services among the elderly despite the wide adoption of smartphones, is that their former workplaces may have been characterized by low IT intensity causing a lower exploratory IT behavior when seniors are retiring (Rockmann et al. 2018). Niehaves and Plattfaut (2014) used the unified theory of acceptance and use of technology (UTAUT) and the model of adoption of technology in households (MATH) to explain internet acceptance and usage by the elderly. Performance expectancy was found to be the main use driver among senior citizens. These models were able to predict how the elderly could be encouraged to learn to use digital technologies.

When asked, the elderly themselves identified several key impeding factors for their digital involvement: fear and anxiety of using digital technology and services, negative attitude, a sense of feeling too old for learning, lack of knowledge, difficulties understanding digital terminology (Holgersson and Söderström 2019). Family support is key for developing mobile internet skill literacy and mobile internet information 
Table 2 Lenses, methods and data sources employed for studying the Digital Divide

\begin{tabular}{|c|c|}
\hline \# & Theories and Concepts \\
\hline 1 & Digital divide concepts. \\
\hline 2 & Social capital, cognitive theories. \\
\hline 3 & $\begin{array}{l}\text { Acculturation theory and models, critical } \\
\text { discourse, critical theory. }\end{array}$ \\
\hline 4 & $\begin{array}{l}\text { Digital divide concepts. 1st order (access) and } \\
\text { 2nd order (usage) of the Digital divide. } \\
\text { Socio-economical concepts. }\end{array}$ \\
\hline 5 & $\begin{array}{l}\text { Concepts from economics and econometrics, } \\
\text { crowdsourcing concepts. }\end{array}$ \\
\hline 6 & $\begin{array}{l}\text { Exploratory study, grounded theory - building } \\
\text { a digital divide evaluation model based on former literatu }\end{array}$ \\
\hline 7 & $\begin{array}{l}\text { Diffusion of innovation, TAM, UTAUT, } \\
\text { social influence. }\end{array}$ \\
\hline 8 & $\begin{array}{l}\text { Socio-economic concepts, household, } \\
\text { digital divide concepts }\end{array}$ \\
\hline 9 & Diffusion of innovation, co-diffusion concepts. \\
\hline
\end{tabular}

10 Sen's capability approach, social inclusion concepts, digital divide concepts.

11 Digital inclusion versus social inclusion, concept of digital enforcement, governmentality, technologies of power

Capital theory; cultural, social, economic capital, habitus. ICT usage behavior model.

No specific theory used, concepts of user behavior, digital media user typologies.

Digital divide concepts (IT use versus inclusion, societal impact) and historical background.

Adoption theory, digital divide dimensions (household characteristics), endogeneity. Socioeconomic characteristics (income, wealth, racial composition, education, age, family-related characteristics).

Technology acceptance, concepts related to access, adoption, and intention to use.

Technology acceptance models. UTAUT, Concepts related to education, gender, income, migration background.

Technology acceptance models. UTAUT, MATH. Behavioral intention theory.

Exploratory approach, no theory, digital divide literature and concepts as background material

Research Methods and Data Sources

Survey data - on individual attitudes, beliefs, and behavioral patterns across 30 European nations.

Qualitative study, four focus groups. In total 28 participants involved with different ethnic backgrounds.

Quantitative survey $(n=440)$ and 102 qualitative interviews. Participants: low-skilled male immigrants.

Secondary data from $28 \mathrm{EU}$ members. 14 variables from Eurostat's Digital Agenda Scoreboard.

Mixed method study, use of publicly available data, data from one crowdsourcing platform and bankruptcy filings.

Quantitative study using AHP (analytical hierarchy process). Data collected from 28 experts to develop a model which was evaluated by 32 participants.

Quantitative study, online questionnaire, 984 responses.

American community survey, data from 820 counties, descriptive statistics, multiple regression analysis

26 countries (13 developed, 13 developing). Data from World Bank and ITU; government reports, corporate estimates, in-country surveys.

Qualitative study; 39 interviews with 53 participants.

Secondary data, world Internet project survey (2017), to discover Internet non-users within countries with a very high development index

Mental simulation experiment. 1030 participants.

Mixed method design, interviews and survey, 447 responses.

Qualitative interpretive research, inquiries at workshops focusing on perceptions among elderly regarding digital exclusion. 6 workshops with 70 participants each time

Quantitative survey, 784 responses.

Survey distributed to the German Federal Employment Agency. 192 participants (seniors) in different age groups.

Mainly a conceptual paper including illustrative quotes from interview data.

Quasi-experimental research design. Dataset: commercial ISPs in USA; customer database from a large US direct marketing company. Customer transactions, household characteristics for several million customers over 12 years.

Survey, 158 SME owners in urban renewal community of Southwestern US.

Quantitative survey, 518 responses in total (192 with age 50 or higher). Interviewed by phone or questionnaire sent out by letter.

Mixed-method study - 100 telephone interviews, mail survey questionnaires, sample of 150 .

Participatory design, workshop with local government in Australia and experts. Participants from local government, Regional Development Australia, and 
Table 2 (continued)

\begin{tabular}{|c|c|c|}
\hline \# & Theories and Concepts & Research Methods and Data Sources \\
\hline & & $\begin{array}{l}\text { others (a mobile app vendor, ICT center of } \\
\text { excellence, academia). }\end{array}$ \\
\hline 23 & $\begin{array}{l}\text { Informed by modernization theories of Sen and } \\
\text { others such as Baliomoune-Lutz. Digital divide } \\
\text { concepts related to socioeconomic dimensions. }\end{array}$ & $\begin{array}{l}\text { Country-level data for } 110 \text { countries from the } \\
\text { World Bank and the World Economic Forum. }\end{array}$ \\
\hline 24 & $\begin{array}{l}\text { Social capital theory. Concepts of societal openness. } \\
\text { Influence of Infrastructure, Affordability, } \\
\text { Innovation. Demographic and Economic factors. }\end{array}$ & $\begin{array}{l}\text { USA state-level data: mostly sourced from NTIA's } \\
\text { Digital Nation Data Explorer collected as part of } \\
\text { the Census Bureau's Current Population and } \\
\text { Community Surveys. }\end{array}$ \\
\hline 25 & Social identity theory, social markedness. & Quantitative study, 83 respondents. \\
\hline 26 & Information infrastructures, socio-technical perspective. & $\begin{array}{l}\text { Qualitative interpretive case study. Thirteen focus } \\
\text { groups - totally } 120 \text { participants. Documents } \\
\text { and reports. }\end{array}$ \\
\hline 27 & $\begin{array}{l}\text { Capital theory. Concepts of trust, awareness and } \\
\text { perceived risk. Coping theory. }\end{array}$ & Qualitative study; interviews - 16 job seekers. \\
\hline 28 & $\begin{array}{l}\text { Social cognitive theory, digital divide concepts, } \\
\text { post-adoptive IT behavior. }\end{array}$ & $\begin{array}{l}\text { Quantitative study, comparing retired and non-retired } \\
\text { persons. Sample of } 219 \text { (157 retired, } 62 \text { non-retired). }\end{array}$ \\
\hline 29 & Technology Acceptance Model. & $\begin{array}{l}\text { Questionnaire, responses from } 37 \text { distressed } \\
\text { city dwellers. }\end{array}$ \\
\hline 30 & $\begin{array}{l}\text { Digital divide concepts related to } \\
\text { socioeconomic dimensions }\end{array}$ & $\begin{array}{l}\text { Data from two representative national samples in } \\
\text { USA for } 2002 \text { and } 2008 \text {. }\end{array}$ \\
\hline 31 & Social cognitive model, computer self-efficacy. & Quantitative survey, 4603 respondents. \\
\hline 32 & $\begin{array}{l}\text { Social support theory; family cognitive support, } \\
\text { emotional support, concepts related to mobile } \\
\text { internet skill, information literacy improvement, } \\
\text { quality improvement. }\end{array}$ & $\begin{array}{l}\text { Online and offline surveys, } 299 \text { questionnaires } \\
\text { ( } 233 \text { online, } 66 \text { offline). Further interviews on } \\
\text { family emotional support. }\end{array}$ \\
\hline 33 & $\begin{array}{l}\text { Digital divide concepts including economic, } \\
\text { social, political, demographic, cultural aspects } \\
\text { and infrastructure. }\end{array}$ & $\begin{array}{l}\text { Country-level data from ITU, the United Nations, } \\
\text { the USA CIA World Factbook and the World Bank. }\end{array}$ \\
\hline
\end{tabular}

literacy among older adults (Xiong and Zuo 2019). Seniors become better positioned to take advantage of digital resources when they have cognitive and emotional support. Cognitive support from family facilitates learning and digital skills' development, and also, the development of skills for judging, analyzing and selecting information (Xiong and Zuo 2019). Emotional support based on patience, praise, encouragement and comfort can help the elderly avoid computer anxiety and stress (Xiong and Zuo 2019). Emotional support is important because unwillingness to adopt advanced digital services by the elderly was found to stem from mistrust, high-risk perceptions, and privacy concerns (Fox and Connolly 2018).

Overall, older people are a heterogeneous group, and it is important not to overlook their differences in digital skills and digital practice. Klier and colleagues conducted a survey on older unemployed individulas in Germany and showed that they can be grouped into four different types of digital media users ranging from very active users (digital contributors) to sceptics with limited or no use (digital sceptics) characterised by their negative attitude towards digital media (Klier et al. 2020). Digitalization efforts should take into account "the various shades of grey in older adults' ability to draw on ITbased innovations" (Lameijer et al. 2017, p. 6).

Marginalized Population Groups Language barriers as for instance, in the case of refugees and immigrants, and practical resource limitations as in the case of distressed urban areas and remote rural areas can cause social exclusion and hinder the process of digital technologies' assimilation throughout society. Several researchers have studied specifically issues related to the digital divide within marginalized population groups. Alam and Imram (2015) found in their research that although refugees and immigrants in the US are motivated to learn about new technology, many are not able to do so because of unaffordable cost, language barriers and lack of skills. Refugees and immigrants realize that technology is helpful for finding new jobs or facilitating social engagement. Digital technologies are of particular value to refugees for multiple reasons: to participate in an information society; to communicate effectively; to understand a new society; to be socially connected; to express their cultural identities (Díaz Andrade and Doolin 2016). A study on mobile communications by labor migrants (Aricat 2015) showed that mobile phones may also facilitate the development of ghettos and 
Inf Syst Front

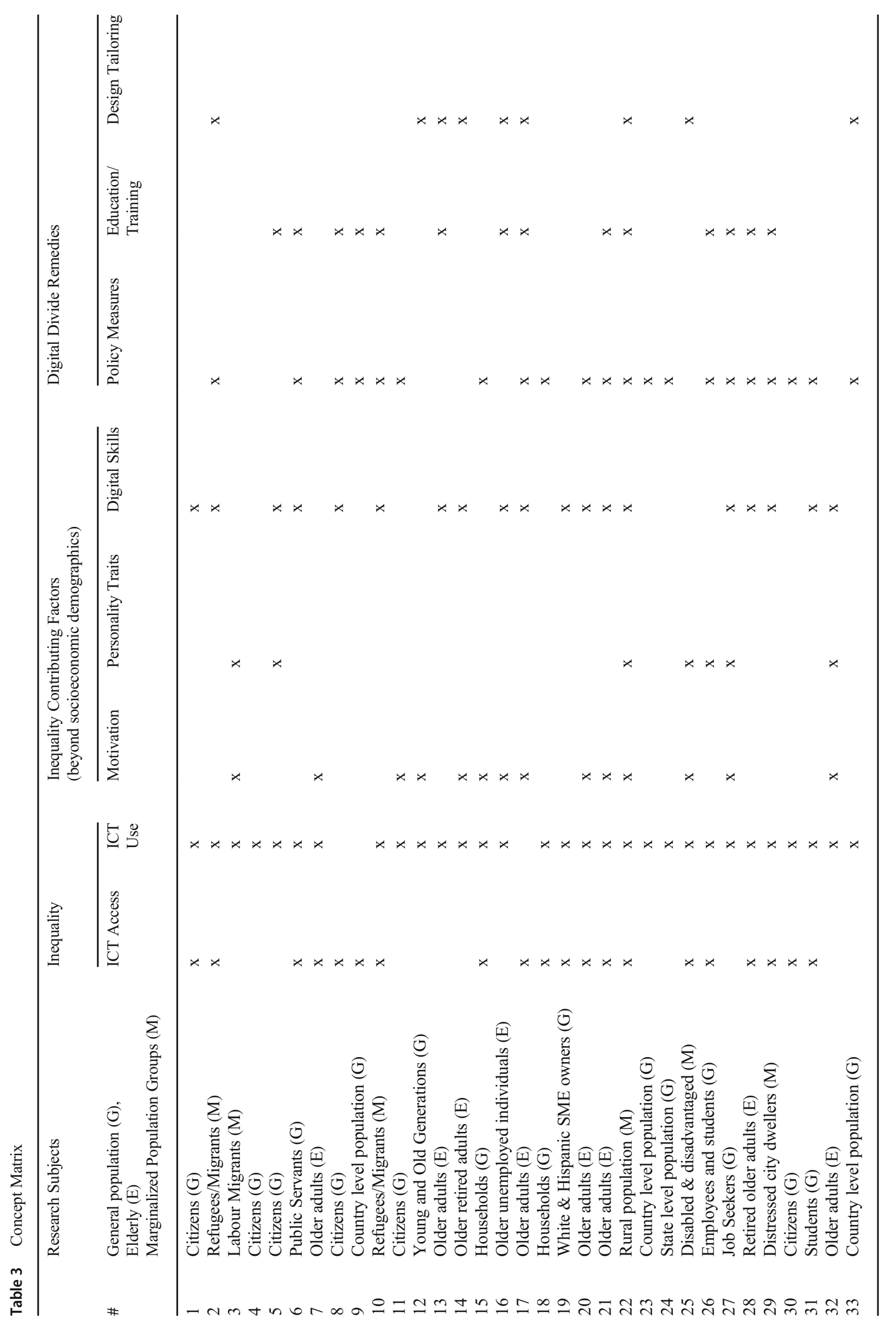

Q Springer 
the lack of integration in the new countries by easing communications between the migrants and their home countries. The study identified a visible divide in the framing of the prospects and potentialities of mobile phones related to acculturation.

Enhancing the relationship between citizens and government through digital services requires reaching out to individuals and communities on the unfortunate side of the divide. Digital technology access and use in the context of egovernment services were explored within one of the most distressed cities in the US (Sipior et al. 2011). This study showed that socioeconomic characteristics (educational level and household income) have significant impact on access barriers, but they also found that employment plays a critical role and is associated both with perceived access barriers and with perceived ease of use. A study conducted among governmental participants representing rural communities in Australia suggests that rural digital exclusion can result from three intertwined layers: availability (elements of infrastructure and connectivity), adoption, and digital engagement (Park et al. 2015). Among these layers, availability is probably not as important as one could expect. Similarly, one large household study conducted across the US found that the availability of Internet Supply Providers (ISP) had little impact on Internet adoption, and that Internet adoption can almost exclusively be attached to differences in household attributes and not to ISP availability (Ma and Huang 2015).

As access gaps are closing in settings with advanced infrastructures and economy, those who do not have access are easily overlooked (Davis et al. 2020). Nevertheless, the firstlevel digital divide still requires attention for marginalized population groups. Furthermore, socioeconomic factors that were found to affect uptake more than two decades ago (for instance, education level and income) are still relevant in today's context for particular segments of our societies. Contrary to traditional views, the availability of digital solutions does not always facilitate the resolution of long-standing problems for those that are less well-off in our societies (for instance, immigrants or financially troubled individuals). What people are actually able to do and achieve with digital technologies relates to their greater positioning in society (Burtch and Chan 2019) and affects their potential for improvement. As digital technologies are becoming indispensable for participating in the economy and engaging in society, sustained digital divides amplify marginalization.

General Population A study by Pick and colleagues (2018) showed the positive influence of managerial/science/arts occupations, innovation, and social capital on the use of digital technologies (Pick et al. 2018). Nevertheless, unreasonably high expectations are found to have a negative impact on ICT acceptance (Ebermann et al. 2016). Findings from a study conducted within White and Hispanic-owned SMEs in the US (Middleton and Chambers 2010) indicate some level of inequality related to ethnicity and age (younger white SME owners being better positioned). Davis and colleagues (Davis et al. 2020) analyzed the influence of income, income distribution, education levels, and ethnicity on levels of access to Internet in the US. The findings show that low levels of education and levels of income below the poverty line still tend to lead to higher proportion of people with no Internet access (Davis et al. 2020). Even when individuals do have equal access to digital technologies, differences in skills can lead to digital inequalities (Burtch and Chan 2019). Taking a differentiated view on skills is needed to understand technology use and no-use (Reinartz et al. 2018). Physical skills matter; users with disabilities can be digitally disadvantaged and despite the benefits promised by specialized assistive technologies their adoption rate falls short of expectations (Pethig and Kroenung 2019).

Some groups may be challenged because they are too far embedded in older systems, which makes it difficult for them to adopt newer ICTs (Abdelfattah 2012). Social capital can trigger ICT awareness changing individual dispositions, thus converting social capital into cultural capital (Reinartz et al. 2018). An interesting study on crowdfunding showed that the benefits of medical crowdfunding accrue systematically less to racial minorities and less educated population segments (Burtch and Chan 2019). One of the reasons for this is the communication-rich nature of the context: less educated persons are not always capable of producing polished, persuasive pitches to solicit funds. Furthermore, digital inequality manifests on the efficacy of using crowdfunding platforms, due to a lack of critical mass in the number of potential transaction partners (donors). The results show the importance of looking beyond access or connectivity to investigate efficacy (in this case, expressed as success in fundraising), and how it associates with different population segments (Burtch and Chan 2019).

At the country level, a number of studies examined socioeconomic influences on access and use of particular forms of technologies as for instance, personal computers and broadband internet (Zhao et al. 2014; Pick and Azari 2011; Dewan et al. 2010). A world-wide study found complementarities in the diffusion of PCs and the Internet leading to narrower digital divides (Dewan et al. 2010). These findings challenge the dominant understanding of characteristics such as country wealth, education levels and telecommunications infrastructure leading to the widening of the digital divide. Countrylevel studies are based on the analysis of data from census surveys, national statistics, and datasets from organizations like UNDP and ITO. The use of such datasets is helpful for performing comparisons across countries but due to the generic nature of data the purpose of digital technology use has been scarcely examined in country-level studies. This may be attributed to the fact that comparable data on specific online activities are not easy to collect across countries (Zhao et al. 
2014). A study conducted by Bucea and colleagues (2020), is an exception to this. The study assessed specifically the use of e-Services and Social Networks within the 28 member-states of the European Union analyzing four socio-demographic factors (age, education, gender, and income). The findings showed that for e-Services, disparities relate mostly to education while for Social Networks age is the most important factor (Bucea et al. 2020). Overall, country level studies are important for assessing disparities across countries and can lead to the identification of factors reinforcing inequalities. At the same time, macro studies can not bring insights about digital inequalities across different population segments within countries.

\subsection{Overcoming Digital Divides}

Policy-making is considered instrumental for closing the digital gap and a mix of policy measures has been suggested in prior research. In general, policy initiatives can include subsidies targeting specific digitally disadvantaged segments as for instance rural populations (Talukdar and Gauri 2011). For instance, governments can apply strong intervention policies to provide equitable ICT access also in rural areas (Park et al. 2015). Furthermore, digital divides may be addressed at scale by crafting policies to equip underprivileged groups with better communication skills (reading, writing, and software use) enabling meaningful engagement with digital platforms (Burtch and Chan 2019). Government policy makers can collaborate with schools to support students from low-income households through the provision of home computers aiming to reduce the effect of socio-economic inequalities among students (Wei et al. 2011). Policies raising the priority of IT, protecting property rights, and enhancing freedom of the press and openness, can help to stimulate educational advances, labor-force participation and income growth, all of which contribute to advancing technology use (Pick and Azari 2011). Policy measures should allow room for local adaptations, as contextual and local elements seem to play a role for technology users and could influence policy success (Racherla and Mandviwalla 2013). Effective evaluation mechanisms make it easier to develop new policies addressing digital divides (Chang et al. 2012) helping policy-makers to refine initiatives targeting certain segments of society, such as elderly people and socio-economically disadvantaged groups (Hsieh et al. 2011).

Contemporary workplaces can help by taking greater responsibility for IT education of their employees even when they are close to retirement. Developing the digital skills of seniors while they are still employed is important for preventing digital exclusion after retirement (Rockmann et al. 2018). Overall, employment has a pivotal role in explaining citizen usage of e-government initiatives (Sipior et al. 2011). As an employee, an individual may have access to the Internet at the place of employment. Furthermore, employment demands may increase the confidence of an individual in performing new tasks. Thinking beyond workplaces, policies that leverage existing communities, social structures, and local actors can also help in reducing digital inequalities (Racherla and Mandviwalla 2013). Such policies can stimulate public/private partnerships with grassroots organizations that already have "hooks" in local communities. Moreover, long-term government policies could set a goal of encouraging growth in social capital within communities (Pick et al. 2018).

Proper training and education can help mitigate digital inequalities (Van Dijk 2012). For instance, platform operators can provide coaching services for underprivileged populations (Burtch and Chan 2019). Furthermore, information campaigns also have a significant role to play, digital divides may be narrowed if vendors engage in trust-building campaigns (Fox and Connolly 2018). Integrating digital education into curricula can also contribute to reducing digital inequalities (Reinartz et al. 2018), and education campaigns can stimulate the adoption and usage of ICTs bridging rural-urban digital gaps. Rural communities typically lag in digital skills, and digital literacy training programs can improve digital engagement in rural communities. Digital literacy programs targeting senior citizens can help them develop the necessary skills and abilities to use digital mobile devices so that they could be part of the Digital Society (Carvalho et al. 2018; Fox and Connolly 2018; Klier et al. 2020). Educational efforts for the elderly must be practically oriented in order to show directly what is to be gained by becoming more digital (Holgersson and Söderström 2019). In addition, social networks, friends and family are important for supporting the training of disadvantaged people in technologies; family emotional and cognitive support can increase the elderly's digital capabilities, reduce computer anxiety and increase trust and motivation for learning (Xiong and Zuo 2019).

The design and development of ICT solutions should take into account individual differences for creating proper stimuli to different user groups. For instance, the use of governmental e-services can be improved by making them more engaging, interactive, and personal to address a country's or region's cultural norms (Zhao et al. 2014). This makes the role of appropriate design for overcoming the digital divide a center of attention. Lameijer et al. (2017) propose that design-related issues should be considered and evaluated to better understand technology adoption patterns among elderly. Also, the study by Klier and colleagues showed that there is a potential to shift older individuals towards a more active engagement with digital media by ensuring ease of use in the design of digital services (Klier et al. 2020). Furthermore, the needs of groups with disabilities ought to be taken into account when designing information systems for the general public (Pethig and Kroenung 2019). It is important to integrate assistive 
functionalities in general IS to emphasize authentic inclusiveness. Overall, research points to the importance of functionalities that suit the needs of specific user groups to stimulate the use of digital technologies.

\section{Crossing Digital Divides: a Research Agenda}

The evolution of IS research on the digital divide during the last decade shows the richness of this research area. As digitalization becomes pervasive in our societies, digital inequalities emerge in different contexts and communities renewing the interest on digital divide research. In recent years, researchers have been shifting away from macro-level studies and are re-orienting towards developing nuanced and contextualized insights about digital inequalities. The analysis of published research allows the identification of gaps and opportunities for further research. Furthermore, there are specific research directions proposed in several of the reviewed papers. The synthesis of suggestions from the papers reviewed with the results of our analysis led to the identification of three research avenues that bring exciting opportunities for researchers to engage with topics that are highly relevant with our digitalization era. Specifically, we suggest a research agenda that proposes: [1] extending established digital divide models with new variables and use of theory, [2] examining the effects of interventions, and [3] addressing societal challenges and especially sustainability goals through the lens of digital divide. Social inclusion and digital equality are crucial for a sustainable digitalized society.

\subsection{Avenue I: Extending Established Digital Divide Models and Use of Theory}

Extant research shows that physical access divides are being reduced in technologically and economically advanced societies but, inequalities in use persist (Hsieh et al. 2011; Lameijer et al. 2017). These use inequalities are found to be related to socioeconomic characteristics and also, personality traits, motivation and digital skills. A better understanding of the complex phenomenon of digital divide is needed combining multiple aspects to form comprehensive models (Choudrie et al. 2018) and further explore the concept itself to get more explanatory power (Lameijer et al. 2017). The emphasis, to date, has been on describing the digital divide by identifying gaps between actual technology access and use against an ideal situation. Work should be undertaken to investigate different national, social and cultural settings (Niehaves and Plattfaut 2010) across geographical contexts (Niehaves and Plattfaut 2014) and the influence of institutional and environmental factors on individuals' ability and motivation to access and use technology (Racherla and Mandviwalla 2013). Furthermore, researchers may explore the values and interests of those abstraining from the use of digital resources and the implications of the overemphasis to digital inclusion (Díaz Andrade and Techatassanasoontorn 2020).

Further research is also needed to extend established models with new variables. Future investigations may add variables related to social theories (Abdelfattah et al. 2010; Hsieh et al. 2011; Niehaves and Plattfaut 2014), personal traits models (Ebermann et al. 2016), and capital theory (Hsieh et al. 2011; Reinartz et al. 2018). Additionally, future research should consider testing psychological variables (Niehaves and Plattfaut 2010) and additional socio-economical aspects (Hsieh et al. 2011; Reisdorf and Rikard 2018) including support from friends and family (Xiong and Zuo 2019; Holgersson and Söderström 2019) to develop a more finegrained understanding of the association between the digital divide phenomenon and contributing variables (Hsieh et al. 2011; Niehaves and Plattfaut 2014; Fox and Connolly 2018). Qualitative research is important for revealing factors that influence inequalities and can become the basis for model building and testing using quantitative data.

Interestingly, fully developed theoretical frameworks that have been extensively used in other streams of exploratory information systems research related to the introduction and use of ICTs were not present in the papers reviewed. For instance, Activity theory and Institutional theory can be used as lenses for understanding and analyzing the digital divide phenomenon. Activity theory (Allen et al. 2011; Engeström 1999) can help in developing a nuanced understanding of the relationship between ICT artifacts and purposeful individuals taking into account the environment, culture, motivations, and complexity of real-life settings. Institutional theory (Jepperson 1991; Scott 2005) can contribute to developing insights related to societal structures, norms and routines shifting attention to units of analysis that cannot be reduced to individuals' attributes or motives. Overall, we observed that digital divide research could benefit from better leveraging theory to extend established digital divide models.

\subsection{Avenue II: Examining the Effects of Interventions to Cross the Digital Divide}

Measures for crossing digital divides include policy interventions, training and design. Information Systems research can be especially relevant by developing design knowledge for the development and deployment of digital technology artifacts in different settings. Although several measures are proposed in the literature, further work is required to research the effect of interventions to avoid the exclusion of citizens from the digital realm addressing inequalities (Alam and Imran 2015; Reisdorf and Rikard 2018; Reinartz et al. 2018). In particular, appropriate design approaches for digital technologies should be investigated and tested to avoid involuntary exclusion of marginalized groups, elderly people or any other group of 
individuals affected by digital inequalities (Rockmann et al. 2018; Lameijer et al. 2017; Alam and Imran 2015; Fox and Connolly 2018). Additionally, comparative research can be undertaken investigating the effects and attractiveness of different design solutions in different cultural settings (Pethig and Kroenung 2019). Overall, although many studies include insights related to measures for bridging digital divides, there is a clear need for studies with a longitudinal research design to investigate the impact of measures over time. Interestingly, little research has been performed up to now on the potentially negative unexpected effects of measures for bridging digital divides (Díaz Andrade and Techatassanasoontorn 2020). This is certainly an area that needs to be further developed. The use of technologies might lead to advantages or disadvantages, which are unevenly distributed in society. Focusing only on benefits, researchers miss the opportunity to connect to emerging literature on the dark side of Internet and unexpected outcomes of digitalization including privacy risks. Scholars of information systems can develop novel avenues of critical thinking on the effects of interventions to cross the digital divide.

\subsection{Avenue III: Linking Digital Divide Research With Research on Sustainability}

There were no studies in our literature review that focused specifically on sustainability topics, and future research should pay attention to this gap. The United Nations' sustainability goals focus on reducing inequality within and among countries to avoid biased economic development, social exclusion, and environmentally untenable practices. Important dimensions of sustainable development are human rights and social inclusion, shared responsibilities and opportunities (United Nations 2020). An essential part of social inclusion in our societies is e-inclusion (Pentzaropoulos and Tsiougou 2014). At the same time, it is important to research the risks and ethical implications of depriving individuals from offline choices (Díaz Andrade and Techatassanasoontorn 2020). Furthermore, we need to support sustainability in rural areas reducing the urban - rural digital divide. Sustainability researchers have identified the issue pointing to the vulnerabilities of rural communities that are in particular need of bridging inequalities (Onitsuka 2019). Future empirical studies on the digital divide should therefore pay attention to sustainability topics in terms of social exclusion and digital inequality to better understand underlying factors and potential remedies.

The covid-19 pandemic made digital inequalities even more evident. In periods of social distancing to minimize infection risks, individuals sustain their connections with colleagues, friends, and family through online connections. Furthermore, people need digital skills to keep updated on crucial information and to continue working when possible using home offices and digital connections. In addition, recent crisis response experiences have shown that switching to digital education may lead to exclusion of the few that cannot afford physical digital tools (Desrosiers 2020), or do not have access to sustainable infrastructures and ICT access. This crisis has shown that digital divides can become a great challenge aggravating inequalities experienced by marginalized communities such as urban poor and under-resourced businesses. Digital inequalities are a major factor of health-related and socio-economical vulnerability (Beaunoyer et al. 2020).

The role of Information Systems researchers is critical for the development of digital capital contributing to sustainable development. Digital capital refers to the resources that can be utilized by communities including digital technology ecosystems and related digital literacy and skills. General policy measures related to stimulating regional economic growth, strengthening tertiary education, or discouraging early leaving from education can be developed by scientists in other domains. However, thinking about inclusive configurations of digital infrastructures and ecosystems and developing related design principles entails specialized knowledge from the Information Systems domain. Furthermore, Information Systems researchers can provide insights about the development of capabilities required for leveraging digital resources such as digital infrastructures (Hustad and Olsen 2020; Grisot and Vassilakopoulou 2017), big data and business analytics (Mikalef et al. 2020). Innovative approaches for leveraging digital resources will be pivotal for addressing grand challenges related to poverty, healthcare and climate change. Information Systems researchers can contribute insights for bridging digital divides to promote an agenda towards a sustainable future.

\section{Conclusions}

The present work takes stock of Information Systems research on the digital divide by synthesizing insights from publications in the 2010-2020 period. The review process was performed with rigor while selecting and critically assessing earlier research. Nevertheless, this work is not without limitations. We have confined the literature search within one specific discipline (Information Systems research). This limits the breadth of the review but facilitates comprehensiveness and depth in the development of insights about the body of literature analyzed. Furthermore, focusing on Information Systems research facilitates the development of a research agenda that is relevant to the target discipline through the identification of gaps and extrapolations from previous work.

The review showed that within digital divide research, the attention of Information Systems research has gradually shifted from access to use and now needs to shift further towards better understanding use outcomes. Digital inequalities 
are a serious threat to civil society in an era where societies are rapidly going digital. For instance, daily activities such as paying bills, filling in application forms, filing tax returns, are all expected to be carried out electronically. There are high expectations for active citizens' role based on online services (Axelsson et al. 2013; Vassilakopoulou et al. 2016); hence, we need to be concerned of digital inequalities ensuring fairness and inclusiveness. Furthermore, digital resources such as big data and business analytics are key enablers of sustainable value creation within societies (Pappas et al. 2018; Mikalef et al. 2020). Bridging digital divides is critical for sustainable digitalized societies. The findings of this literature review can provide a foundation for further research and a basis for researchers to orient themselves and position their own work.

Supplementary Information The online version contains supplementary material available at https://doi.org/10.1007/s10796-020-10096-3.

Acknowledgements We want to acknowledge June Lithell Hansen and Andreas Skaiaa for their contribution in an early stage of this study during fall 2018. The contribution was part of their master course work performed at the University of Agder.

\section{References}

Abdelfattah, B. M. (2012). Individual-multinational study of internet use: the digital divide explained by displacement hypothesis and knowledge-gap hypothesis. In AMCIS 2012 Proceedings. 24. https://aisel.aisnet.org/amcis $2012 /$ proceedings/ AdoptionDiffusionIT/24.

Abdelfattah, B. M., Bagchi, K., Udo, G., \& Kirs, P. (2010). Understanding the internet digital divide: an exploratory multination individual-level analysis. In AMCIS 2010 Proceedings. 542. https://aisel.aisnet.org/amcis2010/542.

AIS (2019). Association for information systems. Senior scholars' basket of journals. https://aisnet.org/page/SeniorScholarBasket. Accessed 10 Jan 2019.

Alam, K., \& Imran, S. (2015). The digital divide and social inclusion among refugee migrants: A case in regional Australia. Information Technology \& People, 28(2), 344-365.

Allen, D., Karanasios, S., \& Slavova, M. (2011). Working with activity theory: Context, technology, and information behavior. Journal of the American Society for Information Science and Technology, 62(4), 776-788.

Aricat, R. G. (2015). Is (the study of) mobile phones old wine in a new bottle? A polemic on communication-based acculturation research. Information Technology \& People, 28(4), 806-824.

Axelsson, K., Melin, U., \& Lindgren, I. (2013). Public e-services for agency efficiency and citizen benefit - Findings from a stakeholder centered analysis. Government Information Quarterly, 30(1), 10 22.

Barzilai-Nahon, K. (2006). Gaps and bits: Conceptualizing measurements for digital divide/s. The Information Society, 22(5), 269-278.

Beaunoyer, E., Dupéré, S., \& Guitton, M. J. (2020). COVID-19 and digital inequalities: Reciprocal impacts and mitigation strategies. Computers in Human Behavior, 111, 106424.
Bucea, A. E., Cruz-Jesus, F., Oliveira, T., \& Coelho, P. S. (2020). Assessing the role of age, education, gender and income on the digital divide: evidence for the European Union. Information Systems Frontiers. https://doi.org/10.1007/s10796-020-10012-9.

Burtch, G., \& Chan, J. (2019). Investigating the relationship between medical crowdfunding and personal bankruptcy in the United States: evidence of a digital divide. MIS Quarterly, 43(1), 237-262.

Carvalho, C. V. d., Olivares, P. C., Roa, J. M., Wanka, A., \& Kolland, F. (2018). Digital information access for ageing persons. In ICALT 2018 Proceedings the 8th International Conference on Advanced Learning Technologies, IEEE, 345-347.

Chang, S.-I., Yen, D. C., Chang, I.-C., \& Chou, J.-C. (2012). Study of the digital divide evaluation model for government agencies-a Taiwanese local government's perspective. Information Systems Frontiers, 14(3), 693-709.

Choudrie, J., Pheeraphuttranghkoon, S., \& Davari, S. (2018). The digital divide and older adult population adoption, use and diffusion of mobile phones: a quantitative study. Information Systems Frontiers, 22, 673-695. https://doi.org/10.1007/s10796-018-9875-2.

Davis, J. G., Kuan, K. K., \& Poon, S. (2020). Digital exclusion and divide in the United States: exploratory empirical analysis of contributing factors. In AMCIS 2020 Proceedings. 1. Fully Online Event. https:// aisel.aisnet.org/amcis2020/social_inclusion/social_inclusion/.

Desrosiers, M.-E. (2020). As universities move classes online, let's not forget the digital divide, Policy Options Politiques. https:// policyoptions.irpp.org/magazines/march-2020/as-universitiesmove-classes-online-lets-not-forget-the-digital-divide/. Accessed 25 Mar 2020

Dewan, S., Ganley, D., \& Kraemer, K. L. (2010). Complementarities in the diffusion of personal computers and the Internet: Implications for the global digital divide. Information Systems Research, 21(4), 925-940.

Díaz Andrade, A., \& Doolin, B. (2016). Information and communication technology and the social inclusion of refugees. MIS Quarterly, 40(2), 405-416.

Díaz Andrade, A., \& Techatassanasoontorn, A. A. (2020). Digital enforcement: Rethinking the pursuit of a digitally-enabled society. Information Systems Journal, 12306, 1-14.

DiMaggio, P., Hargittai, E., Celeste, C., \& Shafer, S. (2004). Digital inequality: From unequal access to differentiated use. In Social inequality (pp. 355-400). New YorK: Russell Sage Foundation.

Ebermann, C., Piccinini, E., Brauer, B., Busse, S., \& Kolbe, L. (2016). The impact of gamification-induced emotions on In-car IS adoption - the difference between digital natives and digital immigrants. In 49th Hawaii International Conference on System Sciences (HICSS 2016) Proceedings, IEEE, 1338-1347.

Engeström, Y. (1999). Activity theory and individual and social transformation. In Y. Engeström, R. Miettinen, \& R. L. Punamäki (Eds.), Perspectives on activity theory (Vol. 19, pp. 19-37). Cambridge: Camebridge University Press.

Fox, G., \& Connolly, R. (2018). Mobile health technology adoption across generations: Narrowing the digital divide. Information Systems Journal, 28(6), 995-1019.

Grisot, M., \& Vassilakopoulou, P. (2017). Re-infrastructuring for eHealth: Dealing with turns in infrastructure development. Computer Supported Cooperative Work (CSCW), 26(1), 7-31. https://doi.org/10.1007/s10606-017-9264-2.

Gunkel, D. J. (2003). Second thoughts: toward a critique of the digital divide. New Media \& Society, 5(4), 499-522.

Holgersson, J., \& Söderström, E. (2019). Bridging the gap - Exploring elderly citizens' perceptions of digital exclusion. In ECIS 2019 Proceedings. https://aisel.aisnet.org/ecis2019 rp/28.

Hsieh, J. J., Rai, A., \& Keil, M. (2011). Addressing digital inequality for the socioeconomically disadvantaged through government initiatives: Forms of capital that affect ICT utilization. Information Systems Research, 22(2), 233-253. 
Hustad, E., \& Olsen, D. H. (2020). Creating a sustainable digital infrastructure: the role of service-oriented architecture. Presented at the Centeris conference 2020, forthcoming in Procedia Computer Science, preprint available at: https://www.researchgate.net/ publication/346989191_Creating_a_sustainable_digital infrastructure_The_role_of_service-oriented_architecture.

Int.Telecom.Union (2019). Facts and figs. 2019: measuring digital development. https:/www.itu.int/en/ITU-D/Statistics/Documents/facts/ FactsFigures2019.pdf. Accessed 25 Apr 2020.

Jepperson, R. L. (1991). Institutions, institutional effects, and institutionalism. In W. W. Powell, \& P. J. DiMaggio (Eds.), The new institutionalism in organizational analysis (pp. 143-163). Chicago: University of Chicago Press.

Kitchenham, B. (2004). Procedures for performing systematic reviews. Keele University Technical Report, UK, TR/SE-0401, 1-26.

Klier, J., Klier, M., Schäfer-Siebert, K., \& Sigler, I. (2020). \#Jobless \#Older \#Digital - Digital media user of the older unemployed. In ECIS 2020 Proceedings. Fully Online Event. https://aisel.aisnet.org/ ecis $2020 \_\mathrm{rp} / 206$.

Lameijer, C. S., Mueller, B., \& Hage, E. (2017). Towards rethinking the digital divide-recognizing shades of grey in older adults' digital inclusion. In ICIS 2017 Proceedings. 11. http://aisel.aisnet.org/ icis2017/General/Presentations/11.

Lee, A. S. (2001). Editor's comments: What are the best MIS programs in US business schools? MIS Quarterly, 25(3), iii-vii.

Luo, M. M., \& Chea, S. (2018). Internet village motoman project in rural Cambodia: bridging the digital divide. Information Technology \& People, 21(1), 2-20.

Ma, J., \& Huang, Q. (2015). Does better Internet access lead to more adoption? A new empirical study using household relocation. Information Systems Frontiers, 17(5), 1097-1110.

Middleton, K. L., \& Chambers, V. (2010). Approaching digital equity: is wifi the new leveler? Information Technology \& People, 23(1), 4 22.

Mikalef, P., Pappas, I. O., Krogstie, J., \& Pavlou, P. A. (2020). Big data and business analytics: A research agenda for realizing business value. Information \& Management, 57(1), 103237. https://doi.org/ 10.1016/j.im.2019.103237.

NTIA. (1999). Falling through the net: Defining the digital divide. A report on the telecommunications and information technology gap in America. National Telecommunications and Information Administration. https://www.ntia.doc.gov/legacy/ntiahome/fttn99/ contents.html. Accessed 20 Oct 2019.

Niehaves, B., \& Plattfaut, R. (2014). Internet adoption by the elderly: employing IS technology acceptance theories for understanding the age-related digital divide. European Journal of Information Systems, 23(6), 708-726.

Niehaves, B., \& Plattfaut, R. (2010). The age-divide in private internet usage: a quantitative study of technology acceptance. In AMCIS 2010 Proceedings. 407. https://aisel.aisnet.org/amcis2010/407.

OECD. (2001). Understanding the digital divide. OECD Digital Economy Papers, 49, OECD Publishing, Paris, France. https://doi. org/10.1787/236405667766.

Onitsuka, K. (2019). How social media can foster social innovation in disadvantaged rural communities. Sustainability, 11(2697), 1-24.

Ortiz de Guinea, A., \& Paré, G. (2017). What literature review type should I conduct? 1. In The Routledge Companion to Management Information Systems (pp. 73-82). Abingdon: Routledge.

Pappas, I. O., Mikalef, P., Giannakos, M. N., Krogstie, J., \& Lekakos, G. (2018). Big data and business analytics ecosystems: paving the way towards digital transformation and sustainable societies. Information Systems and eBusiness Management, 16(3), 479-491.

Park, S., Freeman, J., Middleton, C., Allen, M., Eckermann, R., \& Everson, R. (2015). The multi-layers of digital exclusion in rural Australia. In 48th Hawaii International Conference on System Sciences (HICSS 2015) Proceedings, IEEE, 3631-3640.
Pentzaropoulos, G. C., \& Tsiougou, D. (2014). E-inclusion policies for contemporary knowledge economies and societies: an examination of the main issues. Journal of Social Research \& Policy, 5(1), 7789.

Pethig, F., \& Kroenung, J. (2019). Specialized information systems for the digitally disadvantaged. Journal of the Association for Information Systems, 20(10), 1412-1446.

Pick, J., \& Azari, R. (2011). A global model of technological utilization based on governmental, business-investment, social, and economic factors. Journal of Management Information Systems, 28(1), 49-84.

Pick, J., \& Sarkar, A. (2016). Theories of the digital divide: Critical comparison. In 49th Hawaii International Conference on System Sciences (HICSS 2016) Proceedings, IEEE, 3888-3897.

Pick, J., Sarkar, A., \& Parrish, E. (2018). Internet use and online activities in US States: geographic disparities and socio-economic influences. In the 51st Hawaii International Conference on System Sciences (HICSS 2018) Proceedings, IEEE, 3853-3863.

Racherla, P., \& Mandviwalla, M. (2013). Moving from access to use of the information infrastructure: A multilevel sociotechnical framework. Information Systems Research, 24(3), 709-730.

Reinartz, A., Buhtz, K., Graf-Vlachy, L., \& König, A. (2018). Mechanisms of engagement with, and disengagement from, Internet applications: A qualitative study of online job search. In International Conference on Information Systems (ICIS).

Reisdorf, B. C., \& Rikard, R. V. (2018). Digital rehabilitation: a model of reentry into the digital age. American Behavioral Scientist, 62(9), 1273-1290.

Rockmann, R., Gewald, H., \& Haug, M. (2018). Equal access for everyone? A digital divide cascade for retired senior citizens. In ECIS 2018 Proceedings, 30. https://aisel.aisnet.org/ecis2018 rp/30.

Schryen, G., Wagner, G., \& Benlian, A. (2015) Theory of knowledge for literature reviews: an epistemological model, taxonomy and empirical analysis of IS literature. In ICIS 2015 Proceedings. https://aisel. aisnet.org $/ \mathrm{cgi} /$ viewcontent.cgi?article $=1648 \&$ context $=i \operatorname{cis} 2015$.

Scott, W. R. (2005). Institutional theory: Contributing to a theoretical research program. In Ken G. Smith and Michael A. Hitt (eds.) Great minds in management: The process of theory development, 37(2), 460-484. Oxford UK: Oxford University Press.

Sipior, J. C., Ward, B. T., \& Connolly, R. (2011). The digital divide and tgovernment in the United States: using the technology acceptance model to understand usage. European Journal of Information Systems, 20(3), 308-328.

Srivastava, S. C., \& Shainesh, G. (2015). Bridging the service divide through digitally enabled service innovations: evidence from indian healthcare service providers. MIS Quarterly, 39(1), 245-267.

Talukdar, D., \& Gauri, D. K. (2011). Home Internet access and usage in the USA: Trends in the socio-economic digital divide. Communications of the Association for Information Systems, 28(1), 85-98.

UnitedNations (2020). Getting to know the sustainable development goals. https://www.un.org/sustainabledevelopment/sustainabledevelopment-goals/. Accessed 15 Mar 2020.

United Nations (2018). E-government survey 2018, Gearing E-government to support transformation towards sustainable and resilient societies. https://www.unescap.org/resources/e-governmentsurvey-2018-gearing-e-government-support-transformationtowards-sustainable. Accessed 15 Mar 2020.

Van Deursen, A. J., \& Helsper, E. J. (2015). The third-level digital divide: Who benefits most from being online? In Communication and information technologies annual (pp. 29-52). Bingley: Emerald Group Publishing Limited.

Van Dijk, J. A. (2006). Digital divide research, achievements and shortcomings. Poetics, 34(4-5), 221-235.

Van Dijk, J. A. (2012). The evolution of the digital divide: The digital divide turns to inequality of skills and usage. Digital Enlightenment Yearbook, 2012, 57-75. 
Vassilakopoulou, P., Grisot, M., \& Aanestad, M. (2016). Enabling electronic interactions between patients and healthcare providers: a service design perspective. Scandinavian Journal of Information Systems, 28(1), 71-90.

Venkatesh, V., Sykes, T. A., \& Venkatraman, S. (2014). Understanding e-Government portal use in rural India: role of demographic and personality characteristics. Information Systems Journal, 24(3), 249-269.

Webster, J., \& Watson, R. T. (2002). Analyzing the past to prepare for the future: Writing a literature review. MIS Quarterly, 26(2), xiii-xxiii.

Wei, K.-K., Teo, H.-H., Chan, H. C., \& Tan, B. C. (2011). Conceptualizing and testing a social cognitive model of the digital divide. Information Systems Research, 22(1), 170-187.

Xiong, J., \& Zuo, M. (2019). How does family support work when older adults obtain information from mobile internet? Information Technology \& People, 32(6), 1496-1516.

Zhao, F., Collier, A., \& Deng, H. (2014). A multidimensional and integrative approach to study global digital divide and e-government development. Information Technology \& People, 27(1), 38-62.

Publisher's Note Springer Nature remains neutral with regard to jurisdictional claims in published maps and institutional affiliations.

Polyxeni Vassilakopoulou is an Associate Professor at the Department of Information Systems, University of Agder, Norway. Her research focus is on the transformative potential of digital technology and the implications for work, organisations and societies. Prior to joining academia, she worked in management consulting for over a decade. She has published in leading journals including: Information Systems Journal, Journal of Strategic Information Systems, Journal for Computer Supported Collaborative Work, International Journal of Medical Informatics, Health Informatics Journal.
Eli Hustad is a Professor at the Department of Information Systems, University of Agder, Norway. Her research interests pay attention to socio-technical issues related to the impact of digital transformation and the implementation of large-scale information systems in organizations. She has presented her research at several international conferences. She has published her work in journals such as Information Systems Journal, Information Management Systems, Journal of Systems and Software, Journal of Integrated Design \& Process Science, and International Journal of Information Systems and Project Management. 